\title{
A DNA-binding protein from Candida albicans that binds to the RPG box of Saccharomyces cerevisiae and the telomeric repeat sequence of C. albicans
}

\author{
Nobuya Ishii, ${ }^{1}$ Mutumi Yamamoto, ${ }^{1}$ Hans-Werner Lahm, ${ }^{2}$ Shinnji lizumi, \\ Fumie Yoshihara, ${ }^{1}$ Hironobu Nakayama, ${ }^{1}$ Mikio Arisawa ${ }^{1}$ \\ and Yuhko Aoki ${ }^{1}$
}

\footnotetext{
1 Department of Mycology, Nippon Roche Research Center, Kajiwara 200, Kamakura, KanagawaPrefecture, Japan

2 Department of PRPB, F. Hoffman-La Roche AG, Postfach 4070, Basel Switzerland
}

\author{
Author for correspondence: Yuhko Aoki. Tel: +8146747 6773. Fax: +81467465320. \\ e-mail: yuhko.aoki@roche.com
}

Keywords: Candida albicans, transcription factor, RPG box, nuclear protein

\section{INTRODUCTION}

Candida albicans, the major opportunistic fungal pathogen of humans, causes serious systemic disease in immunocompromised patients and topical infections in healthy individuals (Odds, 1988). The fungal cells can undergo morphogenesis under various conditions and it has been reported that transcription factors regulate these phenomena, including morphological change, in viable cells. Only a limited number of studies have been reported, however, about gene regulation in C. albicans. SUC1, a putative zinc finger protein (Kelly \& KwonChung, 1992), and CPH1, a homologue of Saccharo-

Abbreviations: EMSA, electromobility shift assay; GST, glutathione $S$-transferase; UAS, upstream activation sequence.

The DDBJ/EMBLGenBank accession number for the sequence reported in this paper is $D 85862$. myces cerevisiae STE12 (Liu et al., 1994; Malathi et al., 1994), have been reported to be transcription factors in C. albicans. Northern blot analysis has revealed that the transcription level of several C. albicans genes is regulated (i) during the transition between yeast and hyphal forms (reviewed by Gow, 1994; Calderone, 1994; Cannon et al., 1994a), (ii) during white-opaque switching (reviewed by Morrow et al., 1994) and (iii) by the addition and/or deprivation of sugars or amino acids (MAL2, Geber et al., 1992; HEX1, Cannon et al., 1994b; ADH1, Bertram et al., 1996; ARO3, Pereira \& Livi, 1993). Promoter analysis of WH11 (Srikantha et al., 1995), ACT1 (Delbruck \& Ernst, 1993) and DUT1 (McIntosh et al., 1994) was performed in C. albicans, and McIntosh et al. (1994) proposed a putative MCB (MluI cell-cycle box) element in the DUT1 promoter.

The role of Rap1p (repressor-activator protein 1) in regulating transcription has been intensively studied 
Table 1. Strains used in this study

\begin{tabular}{|c|c|c|}
\hline Strain & Genotype & Source/reference \\
\hline \multicolumn{3}{|l|}{ S. cerevisiae } \\
\hline YTF4 & $\begin{array}{l}\text { MATaura3-52 lys2-801 ade2-101 trp1 } 63 \text { his } 3 \Delta 200 \text { leu2 } 2 \Delta 1 \text { arap1: :LEU2 } \\
\text { pRS416/RAP1Xb }\end{array}$ & This study \\
\hline YTF5 & 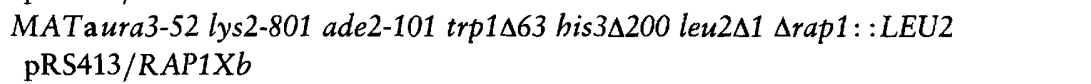 & This study \\
\hline YTF6 & $\begin{array}{l}\text { MATaura3-52 lys2-801 ade2-101 trp1 } \Delta 63 \text { his } 3 \Delta 200 \text { leu } 2 \Delta 1 \Delta \text { rap1 }:: L E U 2 \\
\text { pRS413/rap } 1-2 M n\end{array}$ & This study \\
\hline SFY526 & $\begin{array}{l}\text { MATa ura3-52 his3-200 ade2-101 lys2-801 trp1-901 leu2-3 can }{ }^{\mathrm{r}} \text { gal4-542 gal80-538 } \\
\text { URA3: :GAL1-lacZ }\end{array}$ & Bartel et al. (1993) \\
\hline \multicolumn{3}{|l|}{ C. albicans } \\
\hline IFO 1060 & Wild-type & \\
\hline ATCC 10231 & Wild-type & \\
\hline
\end{tabular}

(reviewed by Shore, 1994). Rap1p works as an activator, usually together with other factors, at a large number of promoters in yeast, including many of the highly transcribed ribosomal protein and glycolytic enzyme genes (Drazinic et al., 1996). The RPG (ribosomal protein genes) box was proposed as a high-affinity DNA sequence for Rap1p (Buchman et al., 1988). In addition, Rap1p engages in regulating telomere length and initiating telomeric silencing through the binding to telomeric repeat sequences characterized by short stretches of $G$ residues (reviewed by Shore, 1996). In this study, we have attempted to identify a DNA-binding protein of C. albicans that could have an important role in the regulation of telomere length as well as gene expression so as to obtain an in-depth insight into the mechanism of transcription in this clinically important organism. Here we report the purification of a $C$. albicans protein (Rbf1p) that binds to the $S$. cerevisiae RPG box and C. albicans telomere sequence, and the expression cloning of its encoding gene. We found that the protein activates transcription in S. cerevisiae and is predominantly present in nuclei. This suggests that the factor is a DNA-binding protein that functions as a transcription factor and/or a telomere-length regulator in C. albicans.

\section{METHODS}

Strains and media. S. cerevisiae and C. albicans strains used in this study are listed in Table 1 . YTF4 was generated by the method described previously by Shore \& Nasmyth (1987)

Table 2. Sequences of the competitor oligonucleotides

\begin{tabular}{|c|c|}
\hline Oligo & Sequence \\
\hline scTPI & 5'-CTATTGATGTTACACCTGGACACCCCTTTTCTGGCT-3' \\
\hline scPGK & 5'-CCAAACTGAAAAAACCCAGACACGCTCGACTTCCTG-3' \\
\hline scADH1 & 5'-TTTTCTGGCAACCACCCATACATCGGGATTCCTATA-3' \\
\hline scRPC40 & 5'-GGATGGATAATTAACCCATACACCTCATACAAGATT-3' \\
\hline scRP39A & 5'-CCGTACAACGAGAACCCATACATTACTTTTTTTAAT-3' \\
\hline scTEF1 & 5'-ACCACTTCAAAACACCCAAGCACAGCATACTAAATT-3' \\
\hline scTEF2 & 5'-ACATTCATGTTGCACCCACACATTTATACACCCAGA-3' \\
\hline scHIS4 & 5'-AATTAATTGCTAAACCCATGCACAGTGACTCACGTT-3' \\
\hline scPMA1 & 5'-ACCGCAGAAATAAACCCATACACGAGACGTAGAACC-3' \\
\hline scTelomere & $5^{\prime}$-СCCACACCCACACACCCACACACCCACACACCCACC-3' \\
\hline klTelomere & $5^{\prime}$-(ACGGATTTGATTAGGTATGTGGTGT) $)_{2}-3^{\prime}$ \\
\hline caTelomere & $5^{\prime}$-(ACGGATGTCTAACTTCTTGGTGT) $)_{2}-3^{\prime}$ \\
\hline $\mathrm{NF} \kappa \mathrm{B}$ & 5'-GATCGAACTGACCGCCCGCGGCCCGT-3' \\
\hline AP2 & 5'-AGTTGAGGGGACTTTCCCAGGC-3' \\
\hline C4G scENO1 & 5'-GATCTAGGATAGCAgCCAAACACCTGCATATTTGGA-3' \\
\hline A11T scENO1 & 5'-GATCTAGGATAGCACCCAAACtCCTGCATATTTGGA-3' \\
\hline C12G scENO1 & 5'-GATCTAGGATAGCACCCAAACAgCTGCATATTTGGA-3' \\
\hline
\end{tabular}


(a)

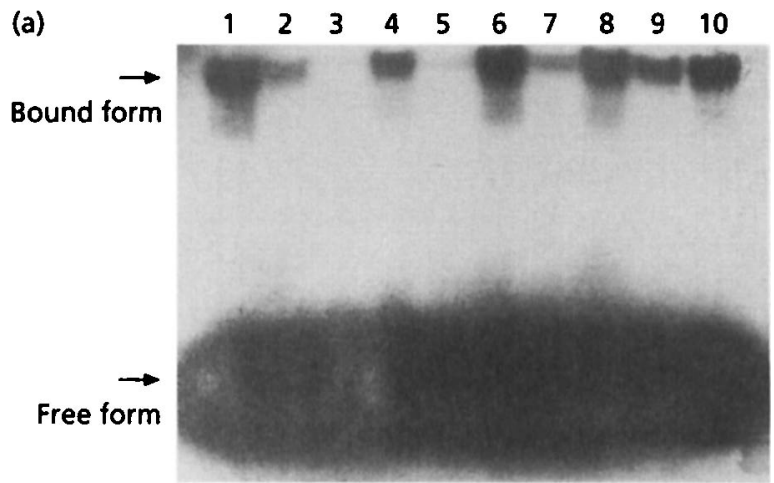

(b)

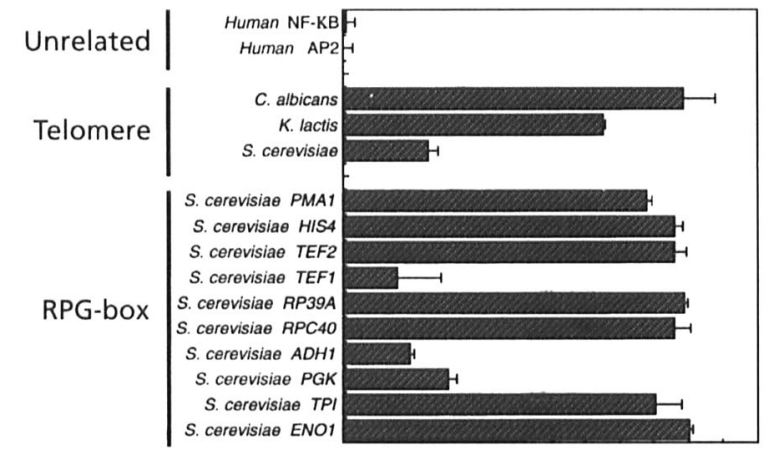

(c)

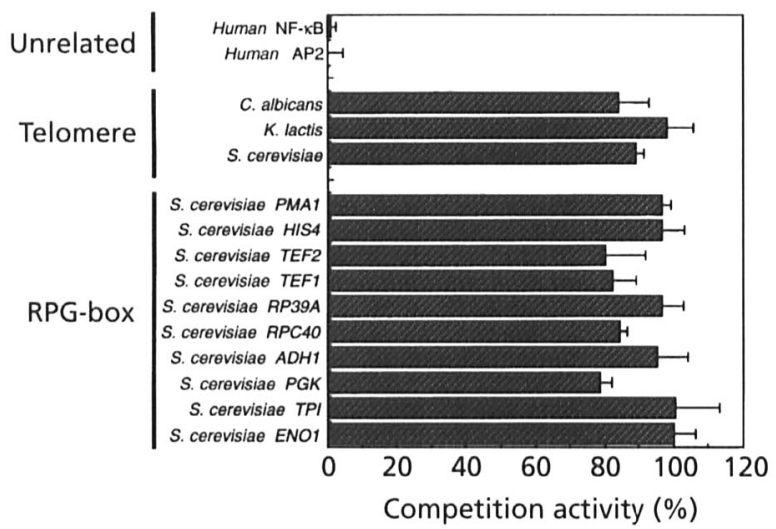

Fig. 1. (a) EMSA in which C. albicans total protein extracts $(2 \mu \mathrm{g}$ per assay) and the radiolabelled 36 bp oligonucleotide probe containing the $S$. cerevisiae ENO1 RPG box (the sequence in Methods) were used. Lanes 1-10 contained probe plus total protein extract; lanes $2,4,6,8$ and 10 contained a 10-fold molar excess of unlabelled oligonucleotides; lanes 3, 5, 7 and 9 contained a 100-fold molar excess of unlabelled oligonucleotides. Lanes: 2 and 3, S. cerevisiae ENO1 RPG box; 4 and 5, S. cerevisiae TPI RPG box; 6 and 7, S. cerevisiae PGK RPG box; 8 and 9 , S. cerevisiae ADH1 RPG box; 10, S. cerevisiae RPC40 RPG box. (b) Quantitative EMSA in which $C$. albicans total protein extracts, the ENO1 RPG box probe and a 10-fold molar excess of unlabelled competitors were used. (c) Quantitative EMSA in which 5 . cerevisiae recombinant Rap1p $(0.2 \mu \mathrm{g}$ per assay) expressed in $E$. coli was used. After the electrophoresis, the radioactivity of the complex forms was quantified by an image analyser. The competition activities were calculated by setting the activity of the ENO1 RPG box as $100 \%$. except haploidal YPH499 (Sikorski \& Hieter, 1989) transfected with pRS416/RAP1X $b$ was used as a host. Plasmid $\mathrm{pRS} 416 / R A P 1 \mathrm{X} b$ was generated by the insertion of a RAP1 EcoRI-Xbal fragment from D56, a gift from D. Shore (Columbia University, USA; Shore \& Nasmyth, 1987), into pRS416 (Sikorski \& Hieter, 1989). Plasmid pRS413/rap1$2 \mathrm{Mn}$ was generated by PCR with the mutagenized oligonucleotide 5' GAAGATTACACTTTGACaATTGCGGTCAAGAAGC $3^{\prime}$ [bold letter and underline indicates rap1-2 mutation (Sussel \& Shore, 1991) and MunI site, respectively]. YTF6 was generated from YTF4 by plasmid shuffling with pRS413/rap1-2Mn. Both S. cerevisiae and C. albicans were routinely grown non-selectively in YPD medium $[1 \%, \mathrm{w} / \mathrm{v}$, yeast extract (Difco); $2 \%, \mathrm{w} / \mathrm{v}$, Bacto peptone (Difco); $2 \%$, $\mathrm{w} / \mathrm{v}$, glucose]. Selection for amino acid prototrophy was performed on SD medium containing $0.67 \%$ Yeast Nitrogen Base (Difco), $2 \%$ glucose, and supplemented with appropriate amino acids. For plasmid shuffling, $0 \cdot 1 \% 5$-fluoroorotic acid was used. All media were solidified by $2 \%(\mathrm{w} / \mathrm{v})$ agar if necessary. Yeast transformation was performed according to Geits et al. (1992). Bacterial transformation was according to Inoue et al. (1990).

DNA-binding assay. For the electromobility shift assay (EMSA), S. cerevisiae ENO1 upstream activation sequence (UAS) (36-mer: 5' GATCTAGGATAGCACCCAAACACCTGCATATTTGGA $\left.3^{\prime}\right)$ was used as a probe. ${ }^{32}$ P-Labelled oligonucleotide ( $10 \mathrm{fmol}$ ) was incubated with protein for $10 \mathrm{~min}$ at $30^{\circ} \mathrm{C}$ in $10 \mu \mathrm{l} 10 \mathrm{mM}$ Tris $/ \mathrm{HCl}$ (pH 7.5) buffer containing $0.5 \mathrm{mM}$ EDTA, $1 \mathrm{mM} \mathrm{MgCl}, 0.5 \mathrm{mM} \mathrm{DTT}$, $50 \mathrm{mM} \mathrm{NaCl}, 0 \cdot 1 \mathrm{mg}$ poly [dI-dC] $\mathrm{ml}^{-1}$ and $4 \%$ (v/v) glycerol. The reaction mixture was subjected to electrophoresis on an $8 \%$ polyacrylamide gel in $25 \mathrm{mM}$ Tris and $192 \mathrm{mM}$ glycine at $4{ }^{\circ} \mathrm{C}$. Following the electrophoresis, gels were dried and radioactivity was quantified by a Mac BAS 1000 image analyser (Fuji film). The sequences of the competitor oligonucleotides are shown in Table 2.

Purification of Rbf1p. C. albicans IFO 1060 was grown aerobically at $30^{\circ} \mathrm{C}$ in 1501 YPD medium. After cells had reached an $\mathrm{OD}_{600}$ of 2.0 , they were harvested (yield $=3.0 \mathrm{~kg}$ wet wt) and frozen. The cells $(300 \mathrm{~g})$ were used for one batch purification, and repeated for 15 cycles. Cells were suspended in $300 \mathrm{ml}$ buffer C (10 mM Tris/HCl, $\mathrm{pH} 8.0 ; 1.5 \mathrm{mM} \mathrm{KCl}$; $0.1 \mathrm{mM}$ EDTA; $0.5 \mathrm{mM}$ DTT; $10 \%$ glycerol; $0.3 \mathrm{M}$ ammonium sulfate; $1 \mathrm{mM}$ PMSF; $2 \mu \mathrm{g}$ chymostatin $\mathrm{ml}^{-1}$; $1.5 \mu \mathrm{g}$ leupeptin $\mathrm{ml}^{-1} ; 5 \mu \mathrm{g}$ antipain $\mathrm{ml}^{-1} ; 1 \mu \mathrm{g}$ pepstatin A $\left.\mathrm{ml}^{-1}, 0.01 \%, \mathrm{v} / \mathrm{v}, \mathrm{NP} 40\right)$, and passed twice through a French pressure cell (Ohtake; French Press 5502) at an output pressure of $1300-1500 \mathrm{~kg} \mathrm{~cm}^{-2}$. The resulting lysate was spun for $120 \mathrm{~min}$ at $13000 \mathrm{~g}$ to remove cell debris. All subsequent purification steps were carried out at $4{ }^{\circ} \mathrm{C}$ unless stated otherwise. The supernatant was applied to a heparin-agarose column (Sigma) equilibrated in $50 \mathrm{mM} \mathrm{KCl} /$ buffer A $(20 \mathrm{mM}$ Tris/HCl, pH 8.0; 0.5 mM EDTA; $0.5 \mathrm{mM} \mathrm{DTT;} 10 \%$ glycerol; $50 \mathrm{mM}$ ammonium sulfate; 0.5 mM PMSF; 0.01\% NP40). Rbf1p was eluted with a linear gradient formed from $50 \mathrm{mM} \mathrm{KCl} /$ buffer A to $1.0 \mathrm{M} \mathrm{KCl} /$ buffer A $(300 \mathrm{ml}$ for each solution developed at $2 \mathrm{ml} \mathrm{min}^{-1}$ ). Active fractions in an EMSA with the ENO1 RPG-box-containing oligonucleotides were collected and dialysed against 11 buffer A, followed by three steps of column chromatography; Mono S (FPLC; Pharmacia), an ssDNA-Cellulose column (Sigma) and a dsDNA-Sepharose column (described below). They were all equilibrated with $50 \mathrm{mM}$ buffer $\mathrm{A}$ and $\mathrm{Rbf} 1 \mathrm{p}$ was eluted with 
Table 3. Purification of Rbf1p from C. albicans IFO 1060

\begin{tabular}{|c|c|c|c|c|c|}
\hline Fraction & $\begin{array}{l}\text { Total } \\
\text { protein } \\
\text { (mg) }\end{array}$ & $\begin{array}{c}\text { Specific } \\
\text { activity } \\
\left(\text { units } \mathbf{~ m g}^{-1}\right)^{*}\end{array}$ & $\begin{array}{l}\text { Total } \\
\text { activity } \\
\text { (units) }\end{array}$ & $\begin{array}{l}\text { Purification } \\
\text { (-fold) }\end{array}$ & $\begin{array}{l}\text { Yield } \\
(\%)\end{array}$ \\
\hline Total protein extract & 17400 & $0 \cdot 010$ & 174 & $1 \cdot 00$ & 100 \\
\hline Heparin-agarose & 109 & 0.65 & 77 & 113 & $40 \cdot 7$ \\
\hline Mono S (FPLC) & $6 \cdot 6$ & $3 \cdot 9$ & 26 & 685 & $14 \cdot 8$ \\
\hline ssDNA-cellulose & 0.22 & 28 & $6 \cdot 3$ & 4860 & 3.60 \\
\hline dsDNA (ENO1 UAS)-agarose & 0.031 & 110 & $3 \cdot 4$ & 19200 & 1.97 \\
\hline Reverse-phase $\left(\mathrm{C}_{4}\right.$ type; HPLC) & NT & $330 \dagger$ & NT & 57600 & NT \\
\hline
\end{tabular}

NT, Not tested.

"One unit of Rbf1p activity is defined as the formation of $1 \mathrm{fmol}$ bound forms with ENO1 RPG-box oligonucleotide.

† Activity of refolded proteins.

a linear gradient from $50 \mathrm{mM} \mathrm{KCl} /$ buffer $\mathrm{A}$ to $1.0 \mathrm{M} \mathrm{KCl} /$

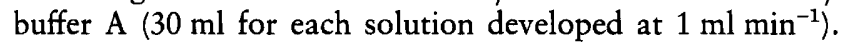
These activities were monitored by an EMSA. Desalting at each step was performed by dialysis against $1150 \mathrm{mM}$ $\mathrm{KCl} /$ buffer $\mathrm{A}$. The dsDNA column was prepared by coupling the 36 bp ENO1 RPG-box-containing oligonucleotides with CNBr-activated Sepharose $4 \mathrm{~B}$ (Pharmacia) according to the method of Kadonaga \& Tjian (1986). The active fractions eluted from the dsDNA column were loaded onto a $\mathrm{C}_{4}$-type reverse-phase column (HPLC; COSMOSIL-C 4 AR; Nakarai) and a linear acetonitrile gradient was developed from $25 \%$ acetonitrile $/ 0.05 \%$ trifluoroacetic acid to $45 \%$ acetonitrile/ $0.05 \%$ trifluoroacetic acid. Each fraction was lyophilized, denatured with a guanidine-containing buffer (50 mM Tris) $\mathrm{HCl}$, pH 7.9; 0.1 mM EDTA; $1 \mathrm{mM} \mathrm{DTT;} \mathrm{0.1} \mathrm{mg} \mathrm{BSA} \mathrm{ml}^{-1}$, $0 \cdot 15 \mathrm{NaCl}, 0 \cdot 1 \% \mathrm{NP} 40,6 \mathrm{M}$ guanidine. $\mathrm{HCl}$ ) and refolded by the method described by Watanabe et al. (1990), followed by the measurement of DNA-binding activity by an EMSA. Active fractions of the HPLC column, which included 60 and $55 \mathrm{kDa}$ proteins, were developed by SDS-PAGE; each band corresponding to 60 or $55 \mathrm{kDa}$ proteins was cut out, and each protein was extracted from the acrylamide gel by incubation

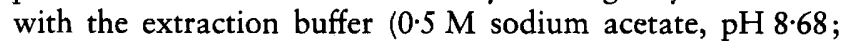
$10 \mathrm{mM}$ magnesium acetate; $1 \mathrm{mM}$ EDTA; $0 \cdot 1 \%$ SDS). These extracted proteins were refolded and assayed by the same method described above.

Amino acid sequence analysis. Tryptic digestion of the purified samples $(33 \mu \mathrm{g} 60 \mathrm{kDa}$ protein and $20 \mu \mathrm{g} 55 \mathrm{kDa}$ protein) onto PVDF membrane was performed by the method described by Fernandes et al. (1994). Micro-bore reversephase HPLC peptide mapping was carried out on a $\mathrm{C}_{8}$ column (Browlee; HP1090A). Peptides were eluted with an acetonitrile gradient in $0.1 \%$ trifluoroacetic acid and peptide-containing fractions were further purified by cation-exchange chromatography (Mini S, Smartsystem; Pharmacia). The fractions were rechromatographed on a Browlee $\mathrm{C}_{8}$ column and then subjected to $\mathrm{N}$-terminal amino acid sequence analysis (Edman sequencer model $470 \mathrm{~A}$; $\mathrm{ABI}$ ).

Anti-Rbf1p antibody generation. Mice were immunized with eluates of the HPLC $\mathrm{C}_{8}$ column, the mixture of 60 and $55 \mathrm{kDa}$ proteins (total $3 \mu \mathrm{g}$ protein), in Freund's complete adjuvant by interperitoneal injection, and boosted twice a month with Freund's incomplete adjuvant. mAbs were prepared from the spleens excised $4 \mathrm{~d}$ after the final boost followed by the method of Campbell (1984). A selection of appropriate hybridomas was performed by a solid-phase assay directly measuring RPG-box-binding activity (M. Yamamoto and others, unpublished). The conditioned media of the hybridomas were used for the immunoscreening and the immunofluorescence microscopy.

Immunoscreening. A C. albicans IFO 1060 cDNA library was generated in the $\lambda Z A$ APII vector using the ZAP-cDNA synthesis kit (Stratagene) according to the manufacturer's instructions. mRNA was prepared from exponentially growing C. albicans IFO 1060 cells in YPD using Oligotex dT30super (Nippon Roche). The library $\left(10^{6}\right.$ independent clones) was transfected to Escherichia coli XL1-Blue and spread onto NZY (Gibco) agar plates with $0.7 \%$ molten agarose-NZY. After a $4 \mathrm{~h}$ incubation at $37^{\circ} \mathrm{C}$, dried nitrocellulose filters, presoaked in $20 \mathrm{mM}$ IPTG, were placed on the plates. After a $2 \mathrm{~h}$ incubation at $42{ }^{\circ} \mathrm{C}$, the filters were removed and then soaked in $5 \%$ skimmed milk/1\% casein for $1 \mathrm{~h}$. Filters were subsequently incubated with anti-Rbf1p antibodies (OA4, OD5) overnight at $4{ }^{\circ} \mathrm{C}$. Bound antibody was detected with alkaline-phosphatase-conjugated anti-IgG. Positive signals which appeared on duplicate filters were plaque-purified by two rounds of re-screening.

Expression of proteins in E. coli. C. albicans $R B F 1$ and $S$. cerevisiae $R A P 1$ genes were fused with glutathione $S$-transferase (GST) in a plasmid, pGEX-4T-1 (Pharmacia), and transformed into $E$. coli strain DH5. In both cases, after the overnight cultivation at $37^{\circ} \mathrm{C}$ with $1 \mathrm{mM}$ IPTG, purification of the soluble fractions was performed by GSH-agarose column chromatography (Sigma) according to Pharmacia's instructions.

In vivo transcriptional activation. The $R B F 1$ fusion with $G A L 4_{\mathrm{BD}}$ was constructed on plasmid pGBT9 (Clontech), and transformed into $S$. cerevisiae SFY526. The plasmid-carrying yeast strains were grown in $2 \mathrm{ml}$ selective medium at $30^{\circ} \mathrm{C}$ to an $\mathrm{OD}_{600}$ of 2.0 and then the specific $\beta$-galactosidase activities were determined as described by Guarente (1983). The $A_{415}$ was measured and assays were normalized to the $\mathrm{OD}_{600}$ of the culture and to the assay time (min). 
(a)

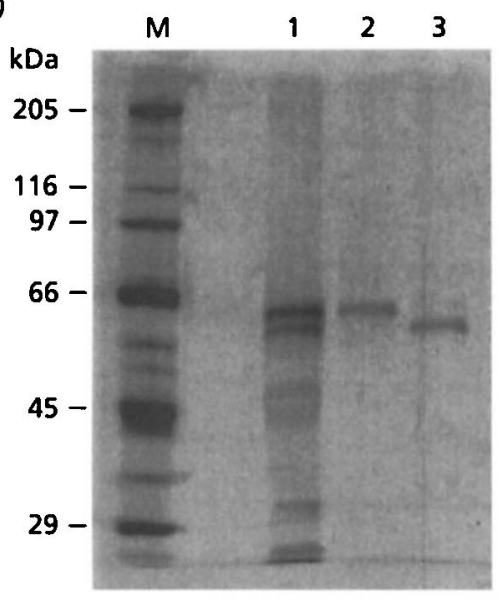

(b)

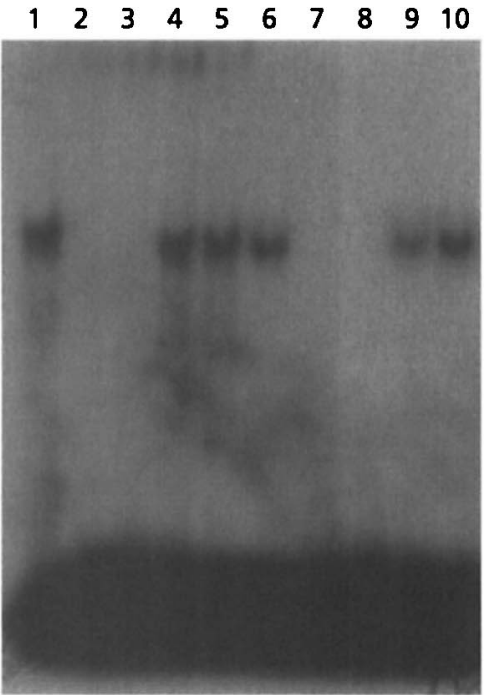

Fig. 2. RPG-box-binding activities and nucleotide recognition profile of 60 and $55 \mathrm{kDa}$ proteins corresponding to Rbf1p activity. (a) SDS-PAGE of gel-purified 60 and $55 \mathrm{kDa}$ proteins with silver staining. The 60 and $55 \mathrm{kDa}$ proteins purified by five steps of column chromatography (Table 1 and Methods) were extracted from the acrylamide gel after SDS-PAGE. Lanes: $M$, molecular mass markers; 1 , fraction 27 of the fifth column chromatography, the microbore $\mathrm{C}_{4}$-type reverse-phase HPLC; 2 and 3, extracted 60 and $55 \mathrm{kDa}$ proteins. (b) EMSA of refolded proteins. Gel-purified $60 \mathrm{kDa}$ (lanes 1-5) and $55 \mathrm{kDa}$ (lanes 6-10) proteins were denatured in guanidine-containing buffer, refolded and assayed in an EMSA $(0.2 \mu \mathrm{g}$ each protein per assay). Lanes 2-5 and 7-10 contained a 100 -fold molar excess of unlabelled oligonucleotides. Lanes: 1 and 6, ENO1 RPG box (ER) probe alone; 2 and $7, E R ; 3$ and 8 , mutated ER (C4G); 4 and 9, mutated ER (C12G); 5 and 10, AP2.

Isolation of nuclei and immunofluorescence of C. albicans spheroplasts. For the isolation of nuclei, we used the protocol of Lue et al. (1991). Preparation of spheroplasts, fixation to poly-L-lysine-coated slides and staining by anti-Rbf1p mAbs and fluorescein-isothiocyanate-conjugated anti-mouse IgG (Jackson Immunoresearch Laboratory) for Rbf1p and $4^{\prime}, 6$ diamidino-2-phenylindole (DAPI; Sigma) for nuclei were followed by the method described by Palladino et al. (1993).
The triple-stained cells were observed and photographed with an epi-illumination fluorescence microscope (SPM-RFL-II; Nikon), according to Yokoyama et al. (1990).

DNA manipulation. Standard recombinant DNA techniques were followed by the methods described by Sambrook et al. (1989). DNA fragments were radioactively labelled with ${ }^{32} \mathrm{P}$ using the Multiprime DNA labelling system (Amersham) and $\left[\alpha^{32} \mathrm{P}\right] \mathrm{dCTP}$ or T4 polynucleotide kinase and $\left[\gamma^{32} \mathrm{P}\right]$ ATP. Hybridization was carried out with rapid hybridization Buffer (Amersham) according to the manufacturer's instructions. The nucleotide sequence was determined with a $373 \mathrm{~A}$ DNA sequencing system (ABI) by the Dye-terminator method according to the manufacturer's instructions.

\section{RESULTS}

RPG-box- and telomeric-repeat-binding activity in the total protein extract of C. albicans

To test whether a specific protein in C. albicans binds to the $S$. cerevisiae RPG box, EMSAs were performed with an end-labelled 36 bp oligonucleotide containing the $S$. cerevisiae ENO1 RPG box. One complex that disappeared by the addition of 10-100-fold unlabelled ENO1 RPG box oligonucleotide was detected (Fig. 1a). Binding competition experiments indicated that this ENO1 RPG-box-binding activity also competed with other RPG boxes in S. cerevisiae, TPI, RPC40, RP39A, TEF2, HIS4 and PMA1. In addition, telomeric repeat sequences of $C$. albicans and Kluyveromyces lactis bound to the protein (Fig. 1b). Whereas other $S$. cerevisiae RPG boxes found in the telomere and promoter regions of the PGK, ADH1 and TEF1 genes had high affinity for the $S$. cerevisiae Rap1 protein (Fig. 1c), these sequences did not compete with this activity (Fig. 1b), suggesting that the nucleotide recognition manner of this RPG-box-binding factor (Rbflp) in C. albicans was not completely the same as that of $S$. cerevisiae Rap1p. Oligonucleotides including the NF$\kappa \mathrm{B}$ - or AP2-binding sequences unrelated to Rap1pbinding sites did not compete with the ENO1 RPG box for either C. albicans $\mathrm{Rbf1p}$ or $S$. cerevisiae Rap1p. The affinity of Rbf1p for the $36 \mathrm{bp}$ ENO1 RPG box was comparable to that of $S$. cerevisiae $\operatorname{Rap} 1 \mathrm{p}\left(K_{\mathrm{d}}\right.$ approximately $2-3 \mathrm{nM}$; data not shown).

\section{Purification of Rbf1p from C. albicans}

To further characterize and determine the amino acid sequence of Rbf1p, we purified it from C. albicans IFO 1060 as described in Methods and in Table 3. Four column chromatography steps resulted in a 19200 -fold purification. In the fourth step, we used affinity chromatography employing the ENO1 RPG-boxconjugated Sepharose column. The 19200-fold enriched preparation was then subjected to reverse-phase chromatography on a microbore $\mathrm{C}_{4}$ HPLC column. Each fraction was assayed for Rbf1p activity in the EMSA after refolding of the protein and after denaturation in the guanidine buffer. Rbf1p activity was detected in association with 60 and $55 \mathrm{kDa}$ proteins in SDS-PAGE. The two proteins had ENO1 RPG-box- 
Table 4. N-terminal amino acid sequences of tryptic fragments of Rbf1p

\begin{tabular}{|ll|}
\hline Fragment & \multicolumn{1}{c|}{ Sequence } \\
\hline 1 & $\mathrm{~N}-\mathrm{K}-\mathrm{P}-\mathrm{D}-\mathrm{E}-\mathrm{P}-\mathrm{G}-\mathrm{H}-\mathrm{N}-\mathrm{E}-\mathrm{E}-\mathrm{N}-\mathrm{S}-\mathrm{R}$ \\
2 & $\mathrm{Q}-\mathrm{A}-\mathrm{Q}-\mathrm{A}-\mathrm{Q}-\mathrm{A}-\mathrm{Q}-\mathrm{A}-\mathrm{Q}-\mathrm{A}-\mathrm{Q}-\mathrm{A}-\mathrm{Q}-\mathrm{R}$ \\
3 & $\mathrm{~T}-\mathrm{L}-\mathrm{V}-\mathrm{E}-\mathrm{K}-\mathrm{P}-\mathrm{I}-\mathrm{N}-\mathrm{K}-\mathrm{P}-\mathrm{H}-\mathrm{H}-\mathrm{H}-\mathrm{X}-\mathrm{L}-\mathrm{L}$ \\
4 & $\mathrm{G}-\mathrm{L}-\mathrm{D}-\mathrm{Q}-\mathrm{P}-\mathrm{D}-\mathrm{A}-\mathrm{A}-\mathrm{V}-\mathrm{I}-\mathrm{A}-\mathrm{A}-\mathrm{I}$ \\
5 & $\mathrm{I}-\mathrm{S}-\mathrm{E}-\mathrm{M}-\mathrm{W}-\mathrm{V}-\mathrm{L}-\mathrm{R}$ \\
6 & $\mathrm{E}-\mathrm{H}-\mathrm{Q}-\mathrm{Q}-\mathrm{L}-\mathrm{Q}-\mathrm{H}-\mathrm{A}-\mathrm{Y}-\mathrm{Q}-\mathrm{Q}-\mathrm{Q}-\mathrm{Q}-\mathrm{Q}-\mathrm{L}-\mathrm{H}-\mathrm{Q}-\mathrm{L}-\mathrm{G}-\mathrm{Q}-\mathrm{L}$ \\
7 & $\mathrm{D}-\mathrm{A}-\mathrm{L}-\mathrm{T}-\mathrm{T}-\mathrm{D}-\mathrm{E}-\mathrm{E}-\mathrm{D}-\mathrm{T}-\mathrm{N}-\mathrm{E}-\mathrm{D}-\mathrm{L}-\mathrm{R}$ \\
8 & $\mathrm{I}-\mathrm{V}-\mathrm{I}-\mathrm{N}-\mathrm{S}-\mathrm{S}-\mathrm{K}-\mathrm{P}-\mathrm{K}$ \\
9 & $\mathrm{~L}-\mathrm{V}-\mathrm{A}-\mathrm{N}-\mathrm{I}-\mathrm{Y}-\mathrm{P}-\mathrm{N}-\mathrm{E}-\mathrm{K}$ \\
\hline
\end{tabular}

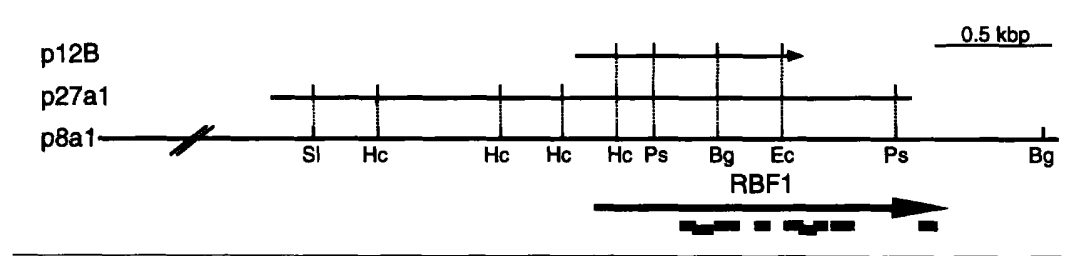

Fig. 3. Restriction map of the $C$. albicans $R B F 1$ locus. p12B (1.0 kbp) was cloned from a CDNA library derived from $C$. albicans IFO 1060 and p27a1 (2.8 kbp) and p8a1 $(8.3 \mathrm{kbp})$ were from a genomic library of C. albicans ATCC 10231. Black rectangles indicate the locus of amino acid sequences determined from the purified Rbf1p. Sl, Sall; Hc, Hincll; Ps, Pstl; Bg, Bg/II; Ec, EcoRI.

binding activity with the same sequence specificity as shown in Fig. 2; tryptic mapping by HPLC of the 60 and $55 \mathrm{kDa}$ proteins also showed they were similar. In addition, the mass analysis of selected HPLC peak fractions revealed the presence of peptides with the same molecular mass (data not shown). These observations are consistent with the notion that the $60 \mathrm{kDa}$ protein is $\mathrm{Rbf} 1 \mathrm{p}$ and the $55 \mathrm{kDa}$ protein may be a shortened fragment of it.

The tryptic fragments separated by the $\mathrm{C}_{8}$ reverse-phase HPLC and cation-exchange chromatography were subjected to $\mathrm{N}$-terminal Edman degradation. The sequences are listed in Table 4.

\section{Immunoscreening of the RBF1 gene}

To clone the $R B F 1$ gene, we raised mAbs against the purified protein (a mixture of 60 and $55 \mathrm{kDa}$ proteins), and a $\lambda$ ZAPII $C$. albicans cDNA library was screened with a mixture of two anti-Rbf1p mAbs, both of which reacted with 60 and $55 \mathrm{kDa}$ proteins in a Western blotting experiment using purified proteins (data not shown). Out of $10^{6}$ plaques, we obtained one positive clone, p12B, which lacked the $3^{\prime}$-terminus of the coding region. By the screening of a genomic library of $C$. albicans with the $\mathrm{p} 12 \mathrm{~B}$ plasmid as a probe, we isolated overlapping DNAs (p27a1 and p8a1) representing approximately 2.8 and $8.3 \mathrm{~kb}$ inserts, respectively (Fig. 3). Nucleotide sequence analysis of a $3.5 \mathrm{~kb}$ Sal I-BglII fragment that reacted with $\mathrm{p} 12 \mathrm{~B}$ revealed a single ORF spanning 1494 nucleotides with no apparent introns. The ORF specifies a protein of 527 aa with a calculated

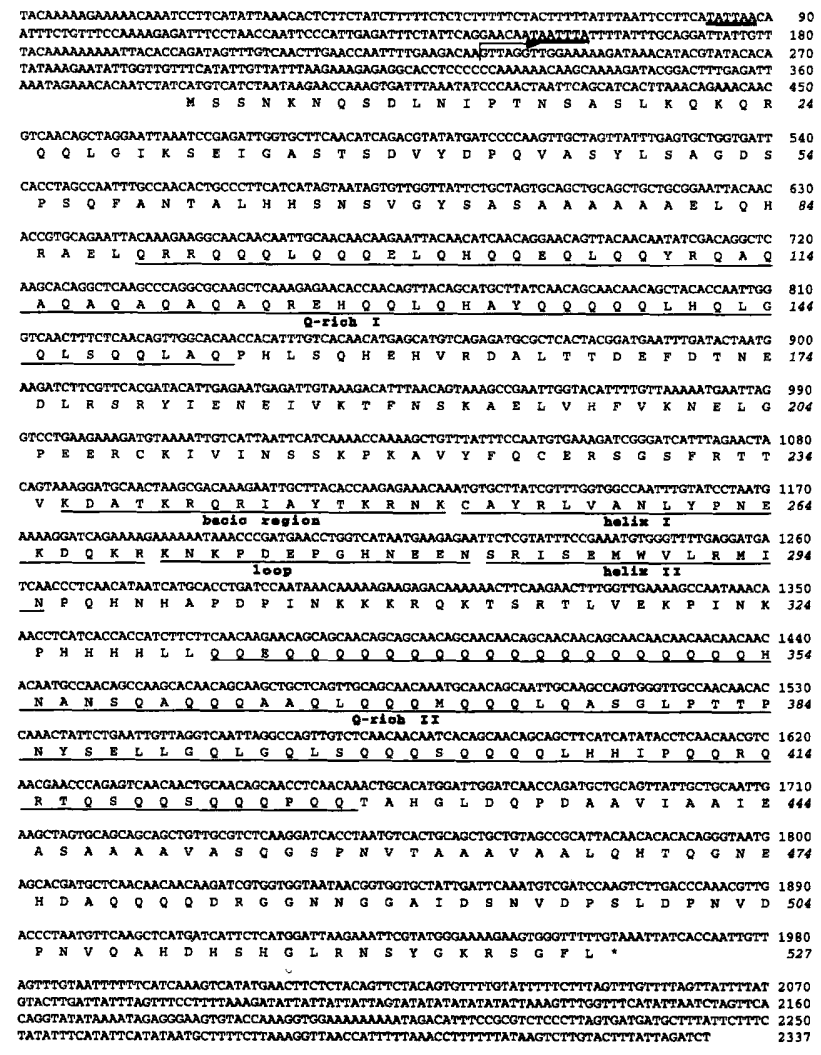

Fig. 4. DNA sequence of the $C$. albicans RBF1 gene and the predicted amino acid sequence of the encoded protein. Putative TATA boxes are thick underlined. The 5 '-end of the cDNA clone p12B is indicated with a bent arrow. 
(a)

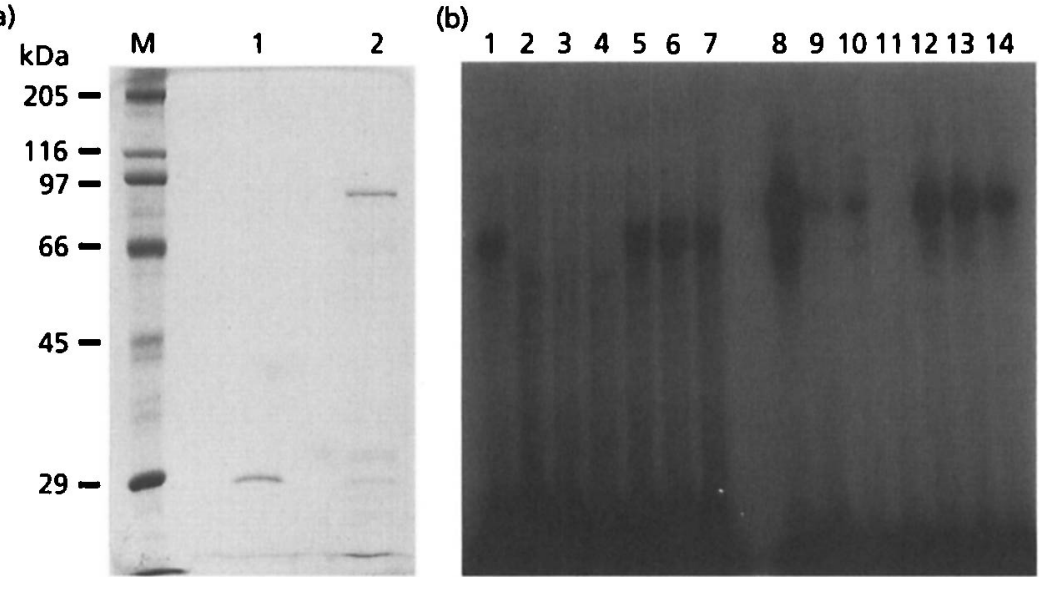

Fig. 5. RPG-box-binding activity and nucleotide recognition profile of the recombinant GST-Rap1p fusion protein. (a) SDS-PAGE of the recombinant protein which was expressed in $E$. coli and purified by a GSH-agarose column. Lanes: $M$, molecular mass markers; 1, GST protein alone; 2, GST-Rbf1p fusion protein. (b) EMSA using a C. albicans total protein extract (lanes 1-7) and the recombinant protein (lanes 8-14). Lanes 2-7 and 9-14 contained a 100-fold molar excess of unlabelled oligonucleotides. Lanes: 2 and 9, ENO1 RPG box (ER); 3 and 10, mutated ER (C4G); 4 and 11, mutated ER (A11T); 5 and 12, mutated ER (C12G); 6 and $13, N F \kappa B ; 7$ and 14, AP2. (a)

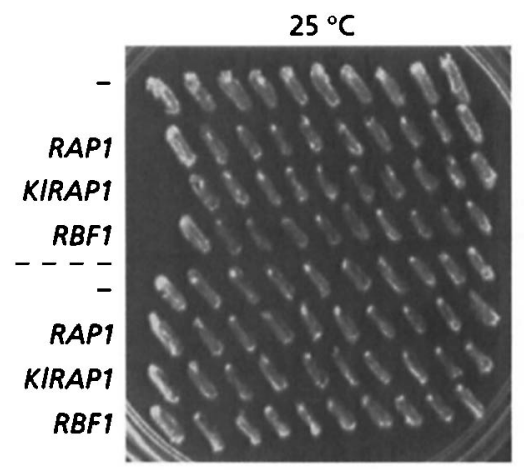

(b) pRS413

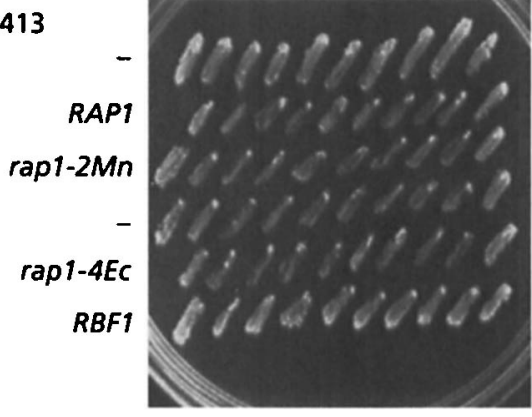

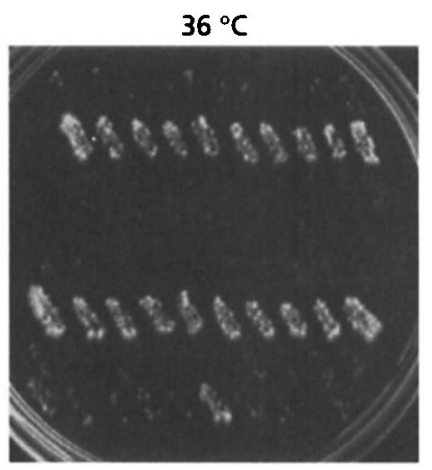

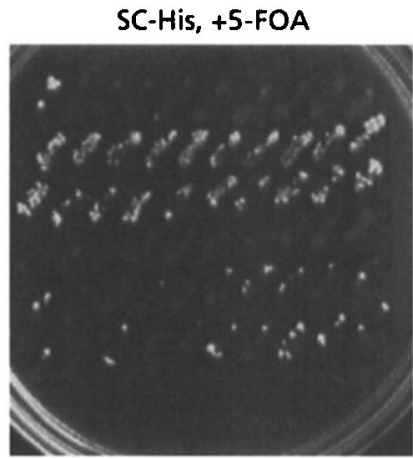

Fig. 6. RBF1 genes complementing the growth-defect phenotype of $S$. cerevisiae rap1 mutants. (a) The $S$. cerevisiae RAPI, $K$. lactis RAP1 and C. albicans RBF1 genes in a low-copy-number (YCp) or a high-copynumber (YEp) plasmid were transformed into the $S$. cerevisiae rap $1^{\text {ts }}$ strain YTF6 (rap1-2). Cells were grown at the permissive temperature $\left(25^{\circ} \mathrm{C}\right)$ or at the restrictive temperature $\left(36^{\circ} \mathrm{C}\right)$. (b) The $\mathrm{S}$. cerevisiae RAP1 (wild-type, rap1-2 or rap1-4) or C. albicans RBFi genes were transformed into the $S$. cerevisiae rap1 disruptant strain YTF5 (rap1::LEU2) harbouring a plasmid, pRS413/RAP1, and the plasmid shuffling was performed by the addition of 5 -fluoroorotic acid (5-FOA) at $25^{\circ} \mathrm{C}$. molecular mass of $59440 \mathrm{Da}$ (Fig. 4). This figure agrees with the previous size estimate of purified Rbf1p. All nine tryptic fragments from which unambiguous sequence information was obtained are precisely represented in different regions of the deduced translation product (Fig. 3). Among these is a peptide that occurs between the first two in-frame $\mathrm{N}$-terminal methionine residues, allowing us to identify the initiator AUG codon. Potential TATA transcriptional regulatory elements are located 228 and 297 nucleotides upstream from the initiator codon. The cDNA clone $\mathrm{p} 12 \mathrm{~B}$ includes the 145 bp $5^{\prime}$-flanking region.

The FASTA and BLAST programs did not reveal any significant similarities between the primary amino acid sequence of the translation product of RBF1 and any entry in the SWISS-PROT database, including $S$. cerevisiae Rap1p (17\% identity). One characteristic of the sequence is that Rbf1p includes many glutamine residues $(21.5 \%)$. As shown in Fig. 4 , Rbf1p has two glutamine-rich regions which are seen in many transcription factors. Another sequence characteristic is its high content of alanine residues $(10.6 \%)$.

To directly establish that the product of the cloned gene was Rbf1p, we expressed it in E. coli as a GST fusion protein and looked for the ENO1 RPG-box-binding activity in an EMSA. Fig. 5 indicates that the expressed 
Table 5. Effects of the overexpression of the RBF1 gene on the growth rates of S. cerevisiae strains

The C. albicans RBF1 gene under the control of the galactose-inducible GAL1 promoter was transformed into S. cerevisiae YTF5 (wild-type) and YTF6 (rap1-2) and cells were grown in a galactose- or glucose-containing medium at $30^{\circ} \mathrm{C}$. Growth rates were monitored by measuring the $\mathrm{OD}_{600}$.

\begin{tabular}{|c|c|c|c|c|}
\hline \multirow[t]{3}{*}{ Conditions } & \multicolumn{4}{|c|}{ Doubling time (h) } \\
\hline & \multicolumn{2}{|c|}{ S. cerevisiae YTF5 } & \multicolumn{2}{|c|}{ S. cerevisiae YTF6 } \\
\hline & pGAL1 & pGAL1-RBF1 & pGAL1 & pGAL1-RBFI \\
\hline With galactose & $5 \cdot 9$ & $6 \cdot 5$ & $5 \cdot 7$ & $7 \cdot 4$ \\
\hline With glucose & 6.9 & $7 \cdot 0$ & $6 \cdot 9$ & $6 \cdot 6$ \\
\hline
\end{tabular}

protein did have binding activity with the same nucleotide recognition manner as that of the native $\mathrm{Rbf} 1 \mathrm{p}$ protein.

\section{RBF1 did not complement the rap ${ }^{\text {ts }}$ mutation in S. cerevisiae}

The RBF1 gene did not complement the growth of $S$. cerevisiae rap $1^{\text {ts }}$ strain YTF6 whether it was put in lowcopy-number (YCp) or high-copy-number (YEp) plasmids, as was the case with the $K$. lactis RAP1 gene (Larson et al., 1994) (Fig. 6a). The plasmid-shuffling experiment also indicated that the $R B F 1$ gene did not rescue the $S$. cerevisiae rap1 disruptant YTF4 (Fig. 6b). The overexpression of Rbflp under the control of the galactose-inducible GAL1 promoter, however, affected the growth of $S$. cerevisiae (Table 5). While the doubling time of Rbf1p-expressing cells was slightly prolonged in a wild-type strain, the growth inhibition was more severe in a mutant strain, rap1-2 (Sussel \& Shore, 1991).

\section{Rbf1p activated transcription in S. cerevisiae}

The function of $R B F 1$ in the transcriptional activation in $S$. cerevisiae was tested by fusing parts of the gene to sequences encoding the Gal4pDNA-binding domain $\left(\mathrm{Gal4}_{\mathrm{BD}}\right)$ (Ma \& Ptashne, 1987). We expected that the hybrid protein would be targeted to $\mathrm{UAS}_{\mathrm{GAL}}$ elements in the chromosome and therefore tested them for the ability to activate a $\mathrm{UAS}_{\mathrm{GAL}}-\mathrm{lac} Z$ reporter gene in an $S$. cerevisiae strain lacking wild-type Gal4p. The hybrid protein was able to activate the reporter gene to significant levels $\left(A_{415} / \mathrm{OD}_{600} \mathrm{~min}^{-1} 40 \cdot 3 \pm 4 \cdot 85\right)$, about ten times higher than that of $\mathrm{Gal} 4_{\mathrm{BD}}$ alone $\left(A_{415} / \mathrm{OD}_{600}\right.$ $\left.\min ^{-1} 4 \cdot 06 \pm 0 \cdot 49\right)$. Since it has been reported that the glutamine-rich regions of transcription factors act as transcription activation domains (Mitchell \& Tjian, 1989), it is considered that the $\mathrm{N}$ - and C-terminal glutamine-rich regions fulfil this function. (a)

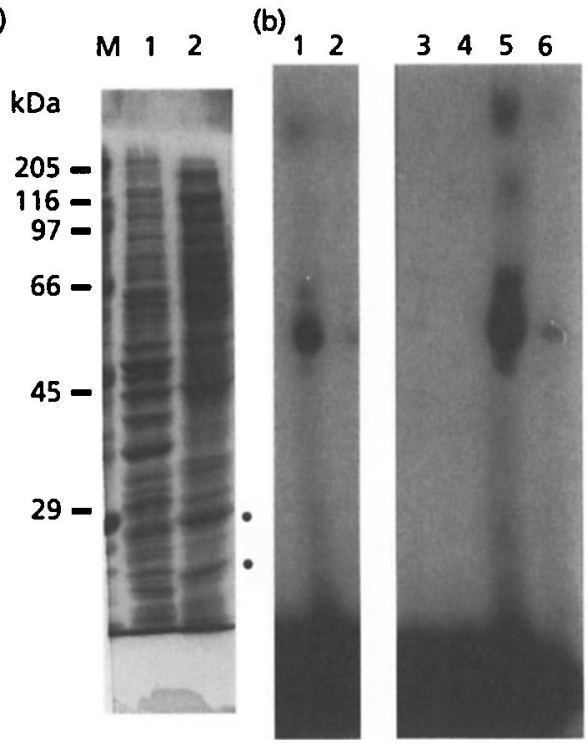

Fig. 7. Rbf1p activity in the nuclear fraction of C. albicans. (a) SDS-PAGE of the total protein (lane 1) and the nuclear (lane 2) fractions. $M$, Molecular mass markers. Histones, prominent components in nuclei, are indicated by two dots. (b) EMSA of the total protein (lanes 1-4) and the nuclear (lanes 5 and 6) fractions. Lanes: $1,80 \mu \mathrm{g}$ protein; 2,3 and $5,8 \mu \mathrm{g}$ protein; 4 and $6,0.8 \mu \mathrm{g}$ protein.

\section{Fractionation of $C$. albicans and confocal immunofluorescence microscopy suggested that Rbf1p was primarily a nuclear protein}

If Rbf1p is a transcription factor or telomere-binding protein, it should be found in nuclei. We used two methods for the analysis of the subcellular location of Rbf1p: (i) fractionation of C. albicans proteins and (ii) confocal immunofluorescence microscopy. In the first method, total cell lysates were fractionated by ultracentrifugation to isolate the nuclei. The resulting fractions in which histones, prominent components in the low-molecular-mass regions of nuclei (Zinser \& 

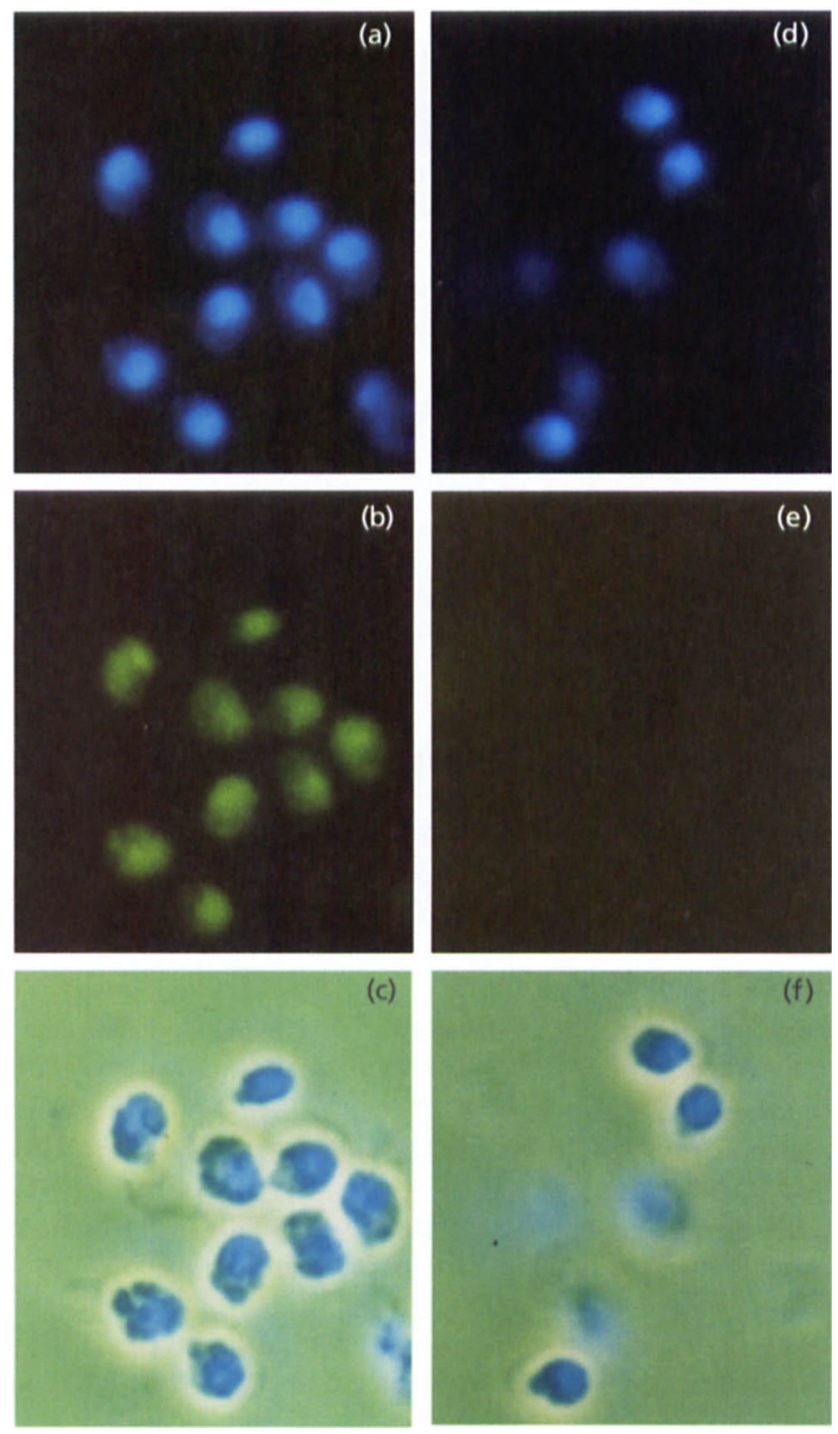

Fig. 8. Confocal immunofluorescence microscopy of $C$. albicans spheroplasts using anti-Rbf1p mAb. Spheroplasts of $C$. albicans fixed to poly-L-lysine-coated slides were stained by the antiRbf1p mAb followed by the fluorescein-isothiocyanate (FITC)conjugated anti-mouse IgG and 4',6-diamidino-2-phenylindole (DAPI) treatment. (a,d) Staining with DAPI; (b) staining with anti-Rap1p mAb and FITC-conjugated anti-mouse IgG; (e) staining with FITC-conjugated anti-mouse IgG alone; $(c, f)$ phase-contrast.

Daum, 1995), were enriched (Fig. 7) were assayed for RPG-box-binding activity in the EMSA. The specific activity of Rbf1p was tenfold higher in the nuclear fraction (Fig. 7). The cis-element recognition profile was determined to be the same as that of purified Rbf1p (data not shown). More direct evidence was obtained by the second method. Incubation of permeabilized C. albicans spheroplasts with the mAb (OA4) preparation revealed diffuse nuclear staining with a weak discernible concentration of antigen at the cytoplasm (Fig. 8). The data presented in Fig. 8 were consistent with the result of the cellular fractionation studies in Fig. 7.

\section{DISCUSSION}

In this paper, we report the purification and cloning of a C. albicans gene encoding a protein that binds to $S$. cerevisiae RPG boxes and C. albicans telomeric repeats. This protein, Rbf1p, was considered to be a new $C$. albicans transcription factor on the basis of several lines of experimental results: (i) it bound to a specific nucleotide sequence; (ii) it could activate transcription in $S$. cerevisiae; (iii) it contained glutamine-rich regions characteristic of transcription factors; and (iv) it was found predominantly in nuclei.

Rap1p proteins from $S$. cerevisiae and $K$. lactis have been identified as RPG-box-binding proteins. Despite a high degree of conservation between the $S$. cerevisiae and $K$. lactis Rap1p proteins $(48.2 \%$ identity in amino acid sequences), especially within the DNA-binding domain $(68.9 \%$ identity), $K$. lactis Rap1p failed to rescue several $S$. cerevisiae rap $1^{\text {ts }}$ mutants at the nonpermissive temperature (Fig. 6a; Larson et al., 1994). The functions that Rap1p plays within a host may be highly specialized within a given species. C. albicans Rbf1p did not have homology with S. cerevisiae or $K$. lactis Rap1p proteins ( $\sim 17 \%$ identity), showed a different nucleotide recognition profile from them, and did not functionally complement $S$. cerevisiae rap1 mutants. These results suggest that its function is distinct from that of the Rap1p family. It was demonstrated, however, that the overexpression of the RBF1 gene caused a growth defect in $S$. cerevisiae. Freeman et al. (1995) reported that the Rap1p DNA-binding domain causes dominant negative growth inhibition when overexpressed, and have speculated that this toxic effect would come from the disturbance of interactions with other proteins after binding to the RPG box or telomeres. This may be considered as one of the reasons for the growth defect in S. cerevisiae caused by Rbflp.

Rbf1p showed binding activity to the C. albicans telomeric repeat sequence. While the repeat in $S$. cerevisiae consists of the $\mathrm{TG}_{1-3}$, the telomeres of other fungi including $C$. albicans often have either irregular or much longer repeats [(ACGGATGTCTAACTTCTTGGTGT) ${ }_{n}$ for C. albicans] (McEachern \& Hicks, 1993; McEachern \& Blackburn, 1994). In S. cerevisiae, Rap1p also binds along the telomeric $\mathrm{TG}_{1-3}$ tracts, where it regulates telomere functions (reviewed by Shore, 1994). Recently, the human telomeric repeat [(TTAGGG) $)_{12}$ ] binding factor (hTRF) has been cloned (Chong et al., 1995). Although the amino acid sequences gave little or no hint about the structural relationship between $S$. cerevisiae Rap1p and hTRF because there was no homology between them (17\%), the three-dimensional structure of the Rap1p DNA-binding domain revealed that myb-type helix-turn-helix (HTH) motifs are concerned with telomere binding (Konig et al., 1996). Rbf1p does not contain this HTH motif, but a variant of the basic helix-loop-helix sequence was suggested between amino acid residues 236 and 295 of Rbf1p (Fig. 4) by secondary structure prediction based on the algorithm of Chou \& Fasman (1978). Further structural com- 
parisons among these telomere-binding factors including those from Schizosaccharomyces pombe (Duffy \& Chambers, 1996), Oxytricha nova (Gray et al., 1991) or Euplotes (Price et al., 1992), whose encoding genes have not yet been cloned, should be of interest, as should the analysis of the effect of Rbf1p on C. albicans telomere length regulation.

In summary, several lines of evidence suggest that Rbf1p is a transcription factor of C. albicans which may be involved in the regulation of telomere function. The phenotypic analysis of the RBF1 disruptants and the identification of the target genes regulated by the factor should provide clues towards understanding the mechanism of regulation of gene expression and telomere control in C. albicans.

\section{ACKNOWLEDGEMENTS}

We thank Dr Yokoyama (Chiba University, Japan) and Dr Machida (Tsukuba Research Center, Japan) for the technical support for immunofluorescence microscopy and for discussion on the Rbf1p purification method, respectively.

\section{REFERENCES}

Bartel, P. L., Chien, C. T., Sternglaz, R. \& Fields, S. (1993). Elimination of false positives that arise in using the two-hybrid system. BioTechniques 14, 920-924.

Bertram, G., Swoboda, R. K., Gooday, G. W., Gow, N. A. R. \& Brown, J.P. (1996). Structure and regulation of the Candida albicans $A D H 1$ gene encoding an immunogenetic alcohol dehydrogenase. Yeast 12, 115-127.

Buchman, A. R., Lue, N. F. \& Kornberg, R. D. (1988). Connections between transcriptional activators, silencers, and telomeres as revealed by functional analysis of a yeast DNA-binding protein. Mol Cell Biol 8, 5086-5099.

Calderone, R. (1994). Molecular pathogenesis of fungal infections. Trends Microbiol 2, 461-463.

Campbell, A. M. (1984). Monoclonal Antibody Technology - The Production and Characterization of Rodent and Human Hybridomas. Amsterdam: Elsevier Science.

Cannon, R. D., Niimi, K., Jenkinson, H. F. \& Shepherd, M. G. (1994a). Molecular cloning and expression of the Candida albicans beta- $\mathrm{N}$-acetylglucosaminidase (HEX1) gene. J Bacteriol 176, 2640-2647.

Cannon, R. D., Timberlake, W. E., Gow, N. A. R. \& 10 other authors (1994b). Molecular biological and biochemical aspects of fungal dimorphism. J Med Vet Mycol Suppl. 1, 53-64.

Chong, L, Steensel, B. V., Broccoli, D., Erdjument-Bromage, H., Hanish, J., Tempst, P. \& Lange, T. (1995). A human telomeric protein. Nature 270, 1663-1667.

Chou, P. Y. \& Fasman, G. D. (1978). Empirical predictions of protein conformation. Annu Rev Biochem 47, 251-276.

Delbruck, S. \& Ernst, J. F. (1993). Morphogenesis-independent regulation of actin transcript levels in the pathogenic yeast Candida albicans. Mol Microbiol 10, 859-866.

Drazinic, C. M., Smerage, J. B., Lopez, M. C. \& Baker, H. V. (1996). Activation mechanism of the multifunctional transcription factor repressor-activator protein 1 (Rap1p). Mol Cell Biol 16, $3187-3196$
Duffy, M. \& Chambers, A. (1996). DNA-protein interactions at the telomeric repeats of Schizosaccharomyces pombe. Nucleic Acids Res 24, 1412-1419.

Fernandes, J., Andrews, L. \& Mische, S. M. (1994). An improved procedure for enzymatic digestion of polyvinylidene difluoridebound proteins for internal sequence analysis. Anal Biochem 218, 112-117.

Freeman, K., Gwadz, M. \& Shore, D. (1995). Molecular and genetic analysis of the toxic effect of RAP1 overexpression in yeast. Genetics 141, 1253-1262.

Geber, A., Williamson, P. R., Rex, J. H., Sweeney, E. C. \& Bennett, J. E. (1992). Cloning and characterization of a Candida albicans maltase gene involved in sucrose utilization. $J$ Bacteriol 174, $6992-6996$.

Geits, D., St Jean, A., Woods, R. A. \& Schiestl, R. H. (1992). Improved method for high efficiency transformation of intact yeast cells. Nucleic Acids Res 20, 1425.

Gow, N. A. R. (1994). Growth and guidance of the fungal hypha. Microbiology 140, 3193-3205.

Gray, J. T., Celander, D. W., Price, C. M. \& Cech, T. R. (1991). Cloning and expression of genes for the Oxytricha telomerebinding protein: specific subunit interactions in the telomeric complex. Cell 67, 807-814.

Guarente, L. (1983). Yeast promoters and lacZ fusions designed to study expression of cloned genes in yeast. Methods Enzymol 101, 181-183.

Inoue, H., Nojima, H. \& Okayama, H. (1990). High efficiency transformation of Escherichia coli with plasmids. Gene 96, 23-28.

Kadonaga, J.T. \& Tjian, R. (1986). Affinity purification of sequence-specific DNA binding proteins. Proc Natl Acad Sci USA 83, 5889-5893.

Kelly, R. \& Kwon-Chung, J. (1992). A zinc finger protein from Candida albicans is involved in sucrose utilization. $J$ Bacteriol 174, 222-232.

Konig, P., Giraldo, R., Chapman, L. \& Rhodes, D. (1996). The crystal structure of the DNA-binding domain of yeast RAP1 in complex with telomeric DNA. Cell 85, 125-136.

Larson, G. P., Castanotto, D., Rossi, J. J. \& Malafa, P. (1994). Isolation and functional analysis of a Kluyveromyces lactis RAP1 homologue. Gene 150, 35-41.

Liu, H., Kohler, J. \& Fink, G. R. (1994). Suppression of hyphal formation in Candida albicans by mutation of a STE12 homolog. Science 266, 1723-1726.

Lue, N. F., Flanagan, P. M., Kelleher, R. J., III, Edwards, A. M. \& Kornberg, R. D. (1991). RNA polymerase II transcription in vitro. Methods Enzymol 94, 545-550.

Ma, J. \& Ptashne, M. (1987). A new class of yeast transcription activators. Cell 51, 113-119.

McEachern, M. J. \& Blackburn, E. H. (1994). A conserved sequence motif within the exceptionally diverse telomeric sequences of budding yeasts. Proc Natl Acad Sci USA 91, 3453-3457.

McEachern, M. J. \& Hicks, J. B. (1993). Unusually large telomeric repeats in the yeast Candida albicans. Mol Cell Biol 13, 551-560.

Mcintosh, E. M., Looser, J., Haynes, R. H. \& Peariman, R. E. (1994). MluI site-dependent transcriptional regulation of the Candida albicans 'dUTPase gene. Curr Genet 26, 415-421.

Malathi, K., Ganesan, K. \& Datta, A. (1994). Identification of a putative transcription factor in Candida albicans that can complement the mating defect of Saccharomyces cerevisiae ste12 mutants. J Biol Chem 269, 22945-22951. 
Mitchell, P. J. \& Tjian, R. (1989). Transcriptional regulation in mammalian cells by sequence-specific DNA binding proteins. Science 245, 371-375.

Morrow, B., Ramsey, H. \& Soll, D. R. (1994). Regulation of phasespecific genes in the more general switching system of Candida albicans strain-3153A. J Med Vet Mycol 32, 287-294.

Odds, F. C. (1988). Candida and Candidosis, 2nd edn. London: Baillière Tindall.

Palladino, F., Laroche, T., Gilson, E., Axelrod, A., Pillus, L. \& Gasser, S. M. (1993). SIR 3 and SIR 4 proteins are required for the positioning and integrity of yeast telomeres. Cell 75, 543-555.

Pereira, S. A. \& Livi, G. P. (1993). Cloning and expression of the ARO3 gene encoding DAHP synthase from Candida albicans. Gene 132, 159-165.

Price, C. M., Skopp, R., Krueger, J. \& Williams, D. (1992). DNA recognition and binding by the Euplotes telomere protein. Biochemistry 31, 10835-10845.

Sambrook, J., Fritsch, E. F. \& Maniatis, T. (1989). Molecular Cloning: a Laboratory Manual, 2nd edn. Cold Spring Harbor, NY: Cold Spring Harbor Laboratory.

Shore, D. (1994). RAP1: a protein regulator in yeast. Trends Genet 10, 408-412.

Shore, D. (1996). The means to bind the ends. Nat Struct Biol 3, 491-493.

Shore, D. \& Nasmyth, K. (1987). Purification and cloning of DNA binding protein from yeast that binds to both silencer and activation elements. Cell 51, 721-732.

Sikorski, R. \& Hieter, P. (1989). A system of shuttle vector and yeast host strains designed for efficient manipulation of DNA in Saccharomyces cerevisiae. Genetics 122, 19-27.

Srikantha, T., Chandrasekhar, A. \& Soll, D. R. (1995). Functional analysis of the promoter of the phase-specific WH11 gene of Candida albicans. Mol Cell Biol 15, 1797-1805.

Sussel, L. \& Shore, D. (1991). Separation of transcriptional activation and silencing functions of the RAP1-encoded repressor/activator protein 1: isolation of viable mutants affecting both silencing and telomere length. Proc Natl Acad Sci USA 88, 7729-7753.

Watanabe, H., Wada, T. \& Handa, H. (1990). Transcription factor E4TF1 contains two subunits with different functions. EMBO J9, 841-847.

Yokoyama, K., Kaji, H., Nishimura, K. \& Miyaji, M. (1990). The role of microfilaments and microtubules in apical growth and dimorphism of Candida albicans. J Gen Microbiol 136, 1067-1075.

Zinser, E. \& Daum, G. (1995). Isolation and biochemical characterization of organelles from the yeast Saccharomyces cerevisiae. Yeast 11, 493-536.

Received 5 July 1996; revised 20 September 1996; accepted 8 October 1996. 